\title{
Impact of yogic intervention on mild hypertensive patients
}

\begin{abstract}
Context: Hypertension, a "psychological classical silent killer" is the hallmark of various cardiovascular disorders. The present society modified lifestyle and food pattern create various types of disorders such as Obesity, Diabetes and Hypertension. Hypertension is a one of the psycho-somatic disease.
\end{abstract}

Aims of study: The aim of the present research is to study the "'Impact of Yogic intervention on Mild Hypertensive patients."

Material and methods: A randomized control study was conducted on subjects $(n=32)$ between 30-60 years with Mild hypertension. They were equally divided into experimental group $(n=32)$ and controlled group $(n=32)$. Their fasting blood pressure were recorded before the intervention period, and both the groups were matched for these biochemical parameters. The yoga group was assigned for practice of a yoga module and the controled group $(n=32)$ was assigned for 6 days in a week, for $1 \mathrm{~h}$ in the morning for 6 weeks. Their CV parameters including blood pressure (BP) were recorded before and after the intervention period. they were randomly selected from Polyclinic, Dev Sanskriti Vishwavidyalaya, Gayatrikunj, Hardwar through the method of Accidental sampling. In this study "Experimental Control group design" was used and t-test has been used for statistical analysis. The result showed a significant changes $(\mathrm{p}<0.01)$. The finding reveals that significantly reduced the level of Systolic and Diastolic Blood Pressure of the Hypertensive Patients. Therefore this Research Paper was undertaken to find a safe and effective treatment for Hypertension that is free from any adverse effects and would maintain Blood Pressure.

Result: Yogic intervention significantly reduced the level of Systolic and Diastolic Blood Pressure of the Hypertensive. Therefore this Research Paper was undertaken to find a safe and effective treatment for Hypertension that is free from any adverse effects and would maintain Blood Pressure.

Keywords: hypertension, prayer, pranayama, yog nidra
Volume 3 Issue | - 2018

\section{Saraswati Devi \\ Assistant professor in Yoga Department, University in Haridwar,} India

Correspondence: Saraswati Devi, Assistant professor in Yoga Department, University in Haridwar, India, Email Saraswati4460@gmail.com

Received: May 19,2017 | Published: January 09, 2018

\section{Introduction}

Now a day's High Blood Pressure (HBP) is one among the leading contributors to burden of disease globally. ${ }^{1}$ Almost 80 million U.S adults are suffering with High blood pressure currently. With less than half of those are having controlled Hypertension, $62 \%$ of Cardio vascular diseases and $49 \%$ of Ischemic heart disease are caused due to uncontrolled Hypertension. ${ }^{2}$ Cardiovascular diseases prevalence is high in Indians, among the sean important modifiable risk factor is Hypertension. ${ }^{3}$ High blood pressure is the most common chronic illness in the United States. ${ }^{4}$ It is a condition that is common among people over the age of 35. According to Dr. Suresh Ramasubban, a pulmonary physician at Rush Hospital in Chicago, Blood Pressure is largely the result of two main forces. The first force, called the stroke volume, is the force created as the blood is pumped into the arteries. The second force is created as the arteries resist the blood flow. Hypertension is a type of cardiovascular disease characterized by elevation of blood pressure above the level considered normal for people of similar racial and environmental backgrounds. Because it affects the entire circulatory system, Hypertension can be detrimental to all the major organs, including the heart, brain, and kidneys. Hypertension is defined as "an abnormal condition in which the blood pressure exceeds the accepted normal reading of 140/90". 5 The first number refers to the Systolic Pressure, which occurs when the blood pressure is at its highest when the left ventricle of the heart contracts. The second number, the Diastolic Pressure, is the lowest blood pressure when the heart is at rest. ${ }^{6}$ In present time prevention and management of Hypertension is major public health challenges. In recent decades, different classes of antihypertensive agents were developed and tested in a variety of settings and among different patients. The studies independently and collectively contributed to a universal finding: lowering arterial pressure can remarkably reduce cardiovascular morbidity and mortality rates as well as slow the progression of renal disease, retinopathy, and all-cause deaths. ${ }^{7}$ However, the long-term use of western medicine will produce some side effects, even produce resistance and affect therapeutic efficacy. ${ }^{8}$ Therefore, seeking for a new effective decompression method is an important subject of hypertension treatment.

Yoga, a practice of controlling the mind and body, is an ancient art that began in India over thousands of years ago. Because it involves Yoga Nidra, Pranayam, and Prayer, it is supposed to increase the vitality of the human body, help with concentration, calm the mind, and improve common physical ailments. ${ }^{9}$ The practice is now widely prescribed by doctors in several countries. ${ }^{10,11}$ Yoga Nidra is one of the finest ways to Self Realization. These days Yoga Nidra is practiced as a best-known technique to induce complete physical mental and emotional relaxation. Yoga Nidra is a state of consciousness, which 
is neither sleep nor awaken, neither is it concentration nor hypnotism. It can be defined, as an altered state of consciousness. ${ }^{12}$ According to Hypertension is an excessive out pouring of Acetylcholine from the region of cerebral cortex .but soon the autonomic Nervous System is also stimulated ,especially the Sympathetic Nervous System leading to too much of turn over of Adrenalin and Nor-Adrenalin. When these neuro-harmone circulate in blood they produces a series of changes in the function of different organ, such as Tachycardia, Hypertension etc. Because of the interference with circulation in skeletal muscles there occurs anaerobic cellular metabolism leading to excessive liberation of lactates into the blood, this will rise the occurrence of psychosomatic disease. $^{13}$

\section{Objectives of the study}

To study the efficacy of Yogic intervention in Mild Hypertension.

\section{Hypothesis}

There would be no significant effect of Yogic intervention in Mild Hypertension.

\section{Review of literature}

Okonta, et al. studied on Does Yoga Therapy Reduce Blood Pressure in Patients with Hypertension? : An Integrative Review. Yoga therapy is a multifunctional exercise modality with numerous benefits. Not only does yoga reduce high BP but it has also been demonstrated to effectively reduce blood glucose level, cholesterol level, and body weight, major problems affecting the American society. The completed integrative review provides guidelines for nursing implementation as a complementary treatment of high $\mathrm{BP}^{14}$ conducted a study on changes in blood pressure indices before and after pranayama practice among young volunteers. There was significant decrease $(\mathrm{p}=0.001)$ in heart rate, systolic Blood Pressure, pulse pressure, mean arterial pressure, Rate Pressure Product \& double pressure product after pranayama practice. There was decrease in diastolic BP also after pranayama practice but this change was not statistically significant ${ }^{15}$ conducted a study on subjects with mild to moderate hypertension and reported that yoga can play an important role in risk modification for cardiovascular diseases. ${ }^{16}$

Independent variable: Yogic Intervention (Prayer, Pranayam \&Yoga Nidra)

Dependent variable: Mild Hypertension

Null hypothesis: There is no significant effect of Yogic Intervention on Mild Hypertensive patients.

\section{Research methodology}

Study Procedure: A total of 32 patients of Mild Hypertension of age group 30-60 were randomly selected from the out-patient door (OPD) of the Polyclinic, Dev Sanskriti Vishwavidyalaya, Shantikunj, Haridwar through the method of Accidental sampling. The reading of SBP and DBP were taken before and after administering of Yogic Intervention .The Blood Pressure was measured in selected subjects using mercury Sphygmomanometer in supine, sitting positions before starting Yogic Intervention. Data were collected by questionnaire, checklist and interview by the researcher. The questionnaire included demographic data (age, occupation, marital status, and educational level) and the checklist involved two parts. The first part was related to the examination of the health status and having no recognized diseases and the second part was related to cases effecting blood pressure and data related to the purpose including the scaling of systolic and diastolic blood pressure. For validity and reliability of the tools, we used a German Richter mercurial blood pressure and a Littman status cope. The scientific reliability of blood pressure operative system was compared with results of similar system.

\section{Diagnostic criteria}

Essential Hypertension (EHT) was diagnosed as per the definition of, ${ }^{17}$ systolic blood pressure of $140 \mathrm{mmHg}$ or above and diastolic blood pressure of $90 \mathrm{mmHg}$ or above. The diagnosis will be made based on the Blood pressure measurement and the criteria for normal, Pre hypertension, Hypertension stage1, and Hypertension stage 2 given by $7^{\text {th }}$ report of Joint National committee on prevention, detection, evaluation and treatment of High Blood Pressure (Table 1).

Table I Practice procedure of yogic intervention

\begin{tabular}{lll}
\hline Days & Yogic intervention & Time \\
\hline \multirow{2}{*}{ 6 WEEKS } & Prayer & $5 \mathrm{~min}$ \\
& Nadisodhan pranayam & $15 \mathrm{~min}$ \\
& Yoga Nidra & $30 \mathrm{~min}$ \\
& Total Time & $50 \mathrm{~min}$
\end{tabular}

Hypertension Stage Systolic.B.P Diastolic.B.P

Normal $\rightarrow>120$ or $>80$

Pre Hypertension $\rightarrow 120-139$ or 80-89

Stage1 Hypertension $\rightarrow 140-159$ or $90-99$

Stage2 Hypertension $\rightarrow 160-179$ or $100-109$

\section{Inclusion criteria}

i. Patients of either sex between the age group of 30-60yrs will be selected.

ii. Both freshly detected and treated cases of Essential Hypertension will be selected.

iii. Comorbidity of well controlled DM with essential hypertension will be included for the study. Patients with Hypertension stage 1 - Systolic BP $(>140 \&<160 \mathrm{mmhg})$ or Diastolic BP $(>90$ $\&<100 \mathrm{mmhg}$ ) will be included for the study.

iv. Asymptomatic and symptomatic cases having headache, insomnia, fatigue etc will be taken for the study.

\section{Exclusion criteria}

i. A patient suffering from any other systemic disorders such uncontrolled DM, Renal disorders, Endocrine disorders etc, which interfere with the course of treatment will be excluded.

ii. Patients with secondary hypertension (stage 2- Systolic BP 160179 and Diastolic BP 100-109 and stage 3 Systolic BP $>180$ or Diastolic BP $>110$ ) will be excluded.

iii. Gestational hypertension will be excluded (Table 2).

Yoga Nidra in this study is the simplest method of relaxation which is being practiced in the flat lying position of shavasana and follows the spoken instruction of Yoga instructor. The practice includes the resolve, body part awareness, breath awareness and visualization. 
Nadisodhan pranayam (Alternate Nostril Breathing) Pranayama practice the subject was asked to relax 5 secs before starting and instructed to Inhale through the Left Nostril while keeping the Right Nostril closed with the thumb of Right hand. Retain the breath for a few seconds and Exhale from the Right Nostril with the Middle and Ring Fingers closing the Left Nostril. Then, once again Anhale through the right nostril. Finally, exhale out through the Left Nostril while closing your Right Nostril with the thumb. This is one round Anuloma-Viloma Pranayama and practiced for 10 minutes. Then observe the normal breathing pattern.

Research design: "Experimental Control group design" was adopted in this study.

Follow-up study: Patients were followed for 6 Weeks.

\section{Measurement of blood pressure}

Blood pressure was measured by the auscultator method in the right arm in supine, sitting and standing positions, using a mercury sphygmomanometer with a cuff of $12 \mathrm{~cm}$ width. All the subjects were made to rest for at least 10 mins before taking the readings. The manometer cuff was snugly tied around the arm with tubing on the medial and the lower side. Systolic blood pressure was recorded to the nearest $2 \mathrm{~mm}$ of $\mathrm{Hg}$ at appearance of first Korotkoff sound, and diastolic blood pressure was recorded to the nearest $2 \mathrm{~mm}$ of $\mathrm{Hg}$ at the disappearance of Korotkoff sound. Systolic and diastolic blood pressure was recorded first in supine position, and then the standing position, with cuff tied to the arm. Readings were taken in all three positions and were analyzed. ${ }^{18}$

\section{Tools required}

Sphygmomanometer (Instrument of mercury blood pressure meter).

\section{Statistical analysis}

The statistical analysis was done using SPSS Software. The results of the study were expressed as mean \pm standard deviation (SD). The statistical significance of difference between the various groups was determined by using the student's t-test and a $\mathrm{p}$ value of $<0.05$ and $<0.01$ is considered significant.

\section{Results}

Table 1 gives the mean pre and post SBP values as well as the statistical analysis of data for the hypertension patients. The obtained t-value is 7.68 , which is significant at 0.01 levels. It is shows that Yogic Intervention significant decrease in the SBP values of the Hypertension patients. (Table 2) gives the mean pre and post DBP values as well as the statistical analysis of data for the Hypertension patients. The obtained t-value is 10.94 , which is significant at 0.01 levels. This shows that the Yogic Intervention lead to significant decrease in the DBP values of the Hypertension patients. On the above (Table $1 \&$ Table 2) shows the significance decreases in both SBP and DBP values. So, the Null Hypothesis is rejected. Yogic Intervention decreases the level of Hypertension.

Table2 Null Hypothesis: I there is no significant effect of yogic intervention on systolic blood pressure and. diastolic pressure of hypertensive patients

\begin{tabular}{|c|c|c|c|c|c|c|c|c|c|}
\hline Parameter of blood pressure & Group & Test & No & Mean & SD & SED & Df & t-value & Significance level \\
\hline \multirow{8}{*}{ Systolic pressure (mmHg) } & \multirow[b]{2}{*}{ Control } & Pre & \multirow{2}{*}{-} & 147.3 & 5.06 & \multirow{2}{*}{ - } & \multirow{11}{*}{62} & \multirow{10}{*}{7.68} & \multirow{11}{*}{$\mathrm{P}<0.01 \mathrm{HSL}$} \\
\hline & & Post & & 146.8 & 4.37 & & & & \\
\hline & \multirow{2}{*}{ Experimental } & Pre & \multirow{2}{*}{-} & 147.8 & 5.33 & \multirow{2}{*}{ - } & & & \\
\hline & & Post & & 138.5 & 4.28 & & & & \\
\hline & Control & Post & 32 & 146.8 & 4.37 & 1.08 & & & \\
\hline & Experimental & Post & 32 & 138.5 & 4.28 & & & & \\
\hline & \multirow{2}{*}{ Control } & Pre & & 91.8 & 3.02 & & & & \\
\hline & & Post & \multirow{3}{*}{ - } & 91.7 & 3.04 & & & & \\
\hline \multirow{4}{*}{ Diastolic pressure (mmHg) } & \multirow{2}{*}{ Experimental } & Pre & & 92.5 & 3.15 & & & & \\
\hline & & Post & & 83 & 3.63 & & & & \\
\hline & Control & Post & 32 & 91.7 & 3.04 & & & & \\
\hline & Experimental & Post & 32 & 83 & 3.63 & 0.83 & 62 & 10.4 & $\mathrm{P}<0.01 \mathrm{HSL}$ \\
\hline
\end{tabular}




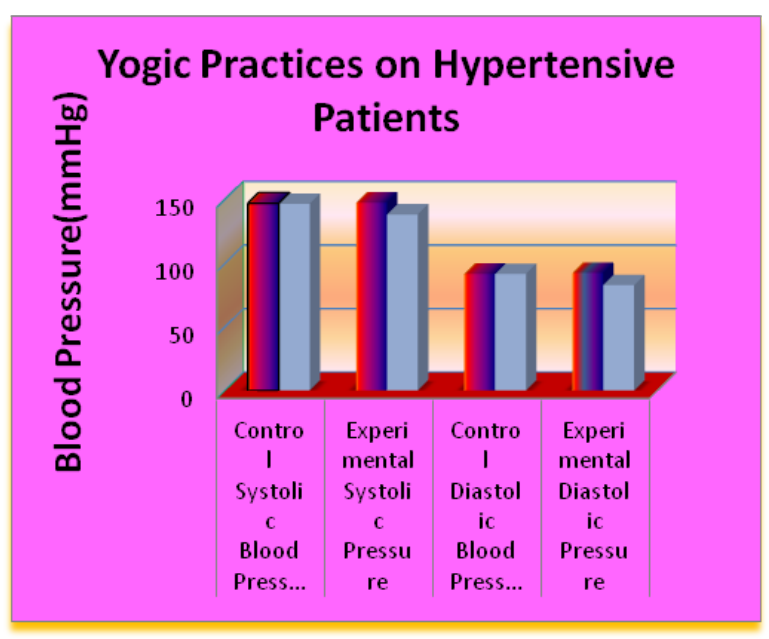

Figure I Yogic intervention decreases the level of hypertension.

\section{Discussion}

Non-pharmacological methods like Yoga, Meditation, Diet, Weight reduction and Life style modification should be encouraged to control the modifiable risk factors the cardiovascular parameters alter with age, but these alterations are slower in persons ageing with regular yoga practice. It can thus be concluded that these results and their explanations would justify the incorporation of yoga as part of our life style in prevention of age related cardiovascular.

Duke University, "when prayer uplifts or calms, it inhibits Cortisol, Epinephrine, and Nor Epinephrine - hormones that flow out of the Adrenal Glands in response to Stress. These fight-or-flight chemicals, released over time can compromise the immune system, upping the odds of developing any number of illnesses, including heart disease, stroke, peptic ulcers, and inflammatory bowel disorder (IBS)." Many experts feel that the immune system is strengthened and nourished by a sense of peace, which can be transferred from one individual to another or used inwardly. Of course, the ancient stories of the Bible and seminal works of Eastern religions link healing with faith. So, it is reasonable to assume that something such as prayer that provides comfort and peace would influence the propensity for you to get disease or how you recover from a disease to Koenig. ${ }^{19}$ Reduction in Heart rate and Blood Pressure indicate a shift in the balancing components of Autonomic Nervous System towards the Parasympathetic activity which was reported by Santha Joseph et al. ${ }^{20}$ Anand $\mathrm{BK}^{21}$ Regular practice of yoga increases the baroreflex sensitivity and decreases the sympathetic tone, there by restoring blood pressure to normal level in patients of essential hypertension was reported by Vijayalakshmi $\mathrm{P}$ et al. ${ }^{22}$ The present study also revealed the significant response in subjects with BMI of $>25$. This may suggest that yoga is more effective in the basal heart rate and blood pressure in morbid conditions like obesity. The study also revealed a highly significant reduction in weight after 6 months of yoga. Similar findings were reported by Jerat $\mathrm{R}$ et al. ${ }^{23}$ Pranayama is a type of yogic breathing exercise. Breathing is the important autonomic function that can be consciously controlled, through which we influence the involuntary nervous system, i.e. establishing the rhythms of breathing which influences the involuntary nervous system and is the key to bring the Sympathetic and Parasympathetic nervous system into harmony. ${ }^{24}$ Yoga Nidra relaxes the physical as well as mental stresses, it relaxes the whole nervous system Stress-related disorders evolve gradually through four stages. In the first stage, psychological symptoms like anxiety and irritability arise due to over activation of the sympathetic Nervous System. ${ }^{25}$ The researchers concluded that this therapy opens a new avenue in the management of Hypertension.

\section{Conclusion}

Supplementary treatments have been researched extensively in recent years. Lifestyle modifications, also termed as nonpharmacologic therapy have an important and expanding role that complements drug therapy. ${ }^{26}$ Also non-pharmacologic therapies can serve as initial therapy in Stage 1 Hypertensive patients, facilitate medication step down or withdrawal in patients with well-controlled Hypertension, and prevent Hypertension in high-risk populations. Current research illustrates that yoga reduces $\operatorname{stress}^{27}$ and that by reducing stress, hypertension can be reduced..$^{27}$ This paper proposes that yoga has a moderating effect on Hypertension. This moderating effect can be used as a supplementary treatment to Hypertension. Yoga practice unites the mind and body activities and offers stress management techniques essential in managing Hypertension. However, it is impossible to conclude that there is a causal relationship. The only way to demonstrate that a continuous practice of yoga actually lowers Hypertension would be to conduct a controlled study that directly tests yoga and its effect on Hypertension.

\section{Strength of study}

The yoga package was designed after extensive literature review by yoga specialists and was a perfect combination of asana and breathing exercises targeted at the disease under study. Excellent compliance of study sample and there were no drop outs. Experimental group patients voluntarily reported to Holistic medicine department and were self motivate for the practice of yoga. The control group was also under constant surveillance by the clinic.

\section{Acknowledgements}

The authors are grateful to the Hospital authority and all the subjects participating in the study for their cooperation.

\section{Conflict of interest}

The author declares no conflict of interest.

\section{References}

1. Raj M, Krishnakumar R. Hypertension inChildren and Adolescents: Epidemiology and Pathogenesis. Indian J Pediatr. 2013;80(1):1-6.

2. Marshall Hagins, Andrew Rundle, Nathan S. Consedine A randomized controlled trial comparing the effects of yoga to an activecontrol on ambulatory blood pressure inindividuals with Pre and Stage 1Hypertension. Journal of Clinical Hypertension Greenwich. Conn. 2014;16(1):54-62.

3. Devi P, Rao M, Sigamani A, et al. Prevalence, risk factors and awareness of hypertension in India: a systematic review. $J$ Hum Hyperten. 2013;27(5):281-287.

4. Sheps SG. Mayo Clinic on High Blood Pressure: Taking Charge of your Hypertension. 2nd ed. Rochester, India: MN: Mayo Clinic Health Information; 2003.

5. Fortmann SP, Breitrose PE. The Blood Pressure Book: How to Get it Down and Keep it Down. Palo Alto, Bull India: CA; 1996. 
6. Rowan RL. How to Control High Blood Pressure Without Drugs. New York, NY: USA; Charles Scribner's Sons; 1986.

7. Lenfant Claude, Chobanian AV, Jones DW, et al. Seventh report of the joint national committee on the prevention, detection, evaluation, and treatment of high blood pressure (JNC 7) Hypertension. JAMA. 2003;289(19):2560 2572 .

8. Cleophas TJ, Grabowsky I, Niemeyer MG, et al. Paradoxical pressor effects of beta-blockers in standing elderly patients with mild hypertension: a beneficial side effect. Circulation. 2002;105(14):1669-1671.

9. Lamb T. Health Benefits of Yoga. Yoga research and education center; 2003 .

10. Deepa T. Effect of yoga and meditation on mild to moderate essential hypertensives. Journal of Clinical and Diagnostic Research. 2012;6(1):2126.

11. Lekh Raj Bali. Long term effect of relaxation on blood pressure and anxiety levels of essential hypertensive males: a controlled study. Psychosom Med. 1979;41(8):637-646.

12. Kumar, Kamakhya. Yoga Nidra: A Historical Review. India; 2010.

13. Udupa KN, Singh RH. The scientific basis of yoga. J Am Med Assn 1972;220(10):1365.

14. Okonta. Does Yoga Therapy reduce blood pressure in patients with hypertension? : an integrative review. Holistic Nursing Practice. 2012;26(3):137-141.

15. Patil Smita V. To study the changes in blood pressure indices before and after pranayama practice among young volunteers" European journal of www.ejpmr.com 474 Yadav. European Journal of Pharmaceutical and MedicalResearch pharmaceutical and medical research. 2016;3(3):305308 .

16. Mahajan AS, Reddy KS, Sachdeva U. Lipid profile of coronary risk subjects following yogic lifestyle intervention. Indian Heart J. 1999;51(1):37-40.
17. $2003 \mathrm{WHO} /$ International society of hypertension (ISH) statement on management of hypertension. J Hypertens. 2003;21(11):1983-1992.

18. He J, Klag MJ, Whelton PK, et al. Body mass and blood pressure in a lean population in Southwest China. Am J Epidemiol. 1994;139(4):380-398.

19. The Proo That Prayer Workshttp://1stholistic.com/prayer/hol_prayer proof.htm

20. Santha Joseph, Sridhar K, Patel SKB, et al. Study of some physiological and biochemical parameters insubjects undergoing yoga training. Indian $J$ medicine res. 1981;74(1):120-124.

21. Anand BK. Yoga and medical seicences. Indian J Physio Pharmocol. 1991;35(2):84-87.

22. Vijayalakshmi P, Madan Mohan, Bhavanani AB, et al. Modulationof stress induced by isometric hand grip test in hypertensivepatients following yogic relaxation. Indian J Physiol Pharmacol. 2004;48(1):59-64.

23. Jerat R, Edry JW, Barnes VA, et al. Physiology of long pranayamic breathing: Neural, respiratory elements may provide a mechanism that explains how slow deep breathing shifts the autonomic nervous system. Med Hypotheses. 2006;67(3):566-571.

24. Saraswati, Swami Satyananda. Training the Mind, Yoga Nidra. 6th ed. India: Bihar School of YogaMunger; 1998. 1710 p.

25. Appel LJ. Non-pharmacologic therapies that reduce blood pressure: A fresh perspective. Clinical Cardiology. 1999;22(7):111-115.

26. Iyengar BKS. Yoga: The Path to Holistic Health. London, UK: England: Dorling Kindersley; 2001.

27. Whitaker J. Reversing Hypertension. New York, USA: NY: Warner Books; 2000 